\title{
Perfil dos pacientes notificados com suspeita de coronavírus em um hospital público do Distrito Federal
}

RESUMO | Objetivo: Analisar o perfil clínico epidemiológico dos pacientes notificados com suspeita de Covid-19 em um hospital público do Distrito Federal, Brasil. Método: Estudo epidemiológico descritivo, quantitativo, com delineamento transversal, pautado em dados da ficha de registro individual de casos de Síndrome Respiratória Aguda Grave do Núcleo de Vigilância Epidemiológica (NUVEI) do Hospital Regional da Asa Norte (HRAN). A coleta de dados ocorreu em etapa única no período compreendido entre 01 e 10 de março de 2021, e a análise estatística descritiva realizada por meio de frequência absoluta e frequência relativa. Resultados: Observou-se maior prevalência de hospitalizações em indivíduos do sexo masculino (53,47\%), com média de idade de 52,25 anos, portadores de doença cardiovascular crônica, e presença de dispneia, tosse e febre. Conclusão: Concluímos que ainda existe muitas lacunas incompreendidas acerca do novo coronavírus, e ressaltamos a importância do preenchimento correto das notificações dos casos suspeitos.

Descritores: Coronavirus; SARS-CoV-2; COVID-19.

\begin{abstract}
Objective: To analyze the clinical epidemiological profile of patients notified with suspected Covid-19 in a public hospital in the Federal District, Brazil. Method: Descriptive, quantitative, cross-sectional epidemiological study, based on data from the individual record form of cases of Severe Acute Respiratory Syndrome of the Epidemiological Surveillance Center (NUVEI) of Hospital Regional da Asa Norte (HRAN). Data collection took place in a single step in the period between March 1 and 10, 2021, and descriptive statistical analysis was performed using absolute frequency and relative frequency. Results: There was a higher prevalence of hospitalizations in male individuals $(53.47 \%)$, with a mean age of 52.25 years, with chronic cardiovascular disease, and presence of dyspnea, cough and fever. Conclusion: We conclude that there are still many ununderstood gaps about the new coronavirus, and we emphasize the importance of correctly filling out the notifications of suspected cases.
\end{abstract}

Descriptors: Coronavirus; SARS-CoV-2; COVID-19

RESUMEN | Objetivo: Analizar el perfil clínico-epidemiológico de los pacientes notificados con sospecha de Covid-19 en un hospital público del Distrito Federal, Brasil. Método: Estudio epidemiológico descriptivo, cuantitativo, transversal, basado en datos del formulario de registro individual de casos de Síndrome Respiratorio Agudo Severo del Centro de Vigilancia Epidemiológica (NUVEI) del Hospital Regional da Asa Norte (HRAN). La recolección de datos se realizó en un solo paso en el período comprendido entre el 1 y el 10 de marzo de 2021, y se realizó un análisis estadístico descriptivo utilizando frecuencia absoluta y frecuencia relativa. Resultados: Hubo mayor prevalencia de hospitalizaciones en varones (53,47\%), con una edad média de 52,25 años, con enfermedad cardiovascular crónica, presencia de disnea, tos y fiebre. Conclusión: Concluimos que aún existen muchas lagunas incomprendidas sobre el nuevo coronavirus, y destacamos la importancia de completar correctamente las notificaciones de casos sospechosos

Descriptores: Coronavirus; SARS-CoV-2; COVID-19

\section{Joerko Campos de Deus}

Enfermeiro. Discente do Programa de Residência Multiprofissional em Urgência e Emergência da Escola Superior de Ciências da Saúde (ESCS). Fundação de Ensino e Pesquisa em Ciências da Saúde (FEPECS). Secretaria de Saúde do Distrito Federal (SES-DF).

ORCID: 0000-0002-7049-3811

\section{Tony José de Souza}

Enfermeiro Doutorando em Saúde Coletiva pela Universidade Federal de Mato Grosso (UFMT). Mestre em Saúde Coletiva pela Universidade Federal de Mato Grosso (UFMT). Coordenador do Curso de Graduação em Enfermagem da União das Faculdades Católicas de Mato Grosso (UNIFACC MT).

ORCID: 0000-0002-6360-4042

\section{Eveliny Barroso da Silva}

Graduada em Estatística pela UFC - Universidade Federal do Ceará (2004), Mestrado em Estatística pela UFSCar - Universidade Federal de São Carlos e Doutorado em Estatística pelo Programa Interintusticional entre a Universidade de São Paulo - USP e a Universidade Federal de São Carlos - UFSCar. Professora Adjunta da Universidade Federal de Mato Grosso (UFMT).

\footnotetext{
Moisés Wesley de Macedo Pereira

Enfermeiro. Mestre em Ciências Médicas pela Universidade de Brasília (UnB). Docente da Escola Superior de Ciências da Saúde (ESCS), Preceptor do Programa de Residência Multiprofissional em Urgência e Trauma da Secretaria de Estado de Saúde do Distrito Federal. ORCID: 0000-0002-8666-5702
}

\section{Aparecida Fátima Camila Reis}

Enfermeira. Docente do Curso de Enfermagem da Universidade Federal de Mato Grosso (UFMT). Doutoranda em Saúde Coletiva pela Universidade Federal de Mato Grosso (UFMT). Mestre em Saúde Coletiva pela Universidade Federal de Mato Grosso (UFMT).

\section{Arthur Cardoso Rezende}

Discente do Curso de Graduação em Estatística pela Universidade Federal de Mato Grosso (UFMT).

Recebido em: 31/08/2021

Aprovado em: 11/10/2021 
INTRODUÇÃO

A COVID-19 é uma doença infecciosa causada pelo novo coronavírus (SARS-CoV-2) e tem como principais sintomas febre, cansaço e tosse seca. Alguns pacientes podem apresentar congestão nasal, dor de cabeça, conjuntivite, dor de garganta, diarreia, perda de paladar ou olfato, erupção cutânea na pele ou descoloração dos dedos das mãos ou dos pés. A transmissibilidade ocorre pelo convívio interpessoal próximo a um caso confirmado devido exposição a gotículas contendo o vírus, além do contato direto com superfícies e objetos contaminados. O SARS-CoV-2 é o agente etiológico responsável pela síndrome respiratória aguda grave (SRAG) 1 .

No início do ano 2020, o mundo foi surpreendido por uma nova doença denominada COVID-192. Em março de 2020, a Organização Mundial de Saúde (OMS) elevou a classificação do SARS-CoV-2 para pandemia, na época 118 países incluindo o Brasil já haviam registrado casos confirmados de síndrome respiratória aguda grave da infecção3. No Brasil, o primeiro caso de novo coronavírus foi confirmado pelo Ministério da Saúde, sendo um homem de 61 anos que deu entrada no Hospital Israelita Albert Einstein, em São Paulo, com histórico de viagem à Itália4. O Brasil ocupava a terceira posição em números de indivíduos contaminados e $2^{\circ}$ lugar com maior número de óbitos atestado em junho de 2021.

Atualmente, a única medida que proporciona a diminuição da crescente incidência de novos casos pelo covid-19 é a imunização em massa. No Brasil há quatro vacinas autorizadas pela Agência Nacional de Vigilância Sanitária (Anvisa), duas de caráter emergencial (Sinovac/Butantan e Janssen) e duas com registro definitivo (AstraZeneca/Fiocruz e Pfizer/Wyeth)6. Outras medidas preventivas contra a infecção seguem mantidas, entre elas, o uso de máscaras, higiene das mãos e

\section{A COVID-19 é uma doença infecciosa causada pelo novo coronavírus (SARS- CoV-2) e tem como principais sintomas febre, cansaço}

e tosse seca. Alguns pacientes podem apresentar congestão nasal, dor de cabeça, conjuntivite, dor de garganta, diarreia, perda de paladar ou olfato, erupção cutânea na pele ou descoloração dos dedos das mãos ou dos pés. o distanciamento social6.

O desnível socioeconômico e extensão geográfica do Brasil têm implicação expressiva na distribuição da doença, considerando as condições de saneamento básico e educacional da população, além da divisão de renda no país7. A distribuição geográfica dos números de covid-19 no Brasil, em junho de 2021, sugere disposições maiores sobre as regiões do sudeste e sul do país, com incidência maior no centro-oeste com 10706,2 por $100 \mathrm{mil}$ habitantes. A capital brasileira, Distrito Federal, é a segunda unidade federativa na região centro-oeste com pouco mais de 410 mil casos registrados8.

Segundo um estudo realizado no Hospital Israelita Albert Einstein que analisou as características clínicas e epidemiológicas dos pacientes, observou-se que as variáveis mais frequentes associado a complicações do quadro clínico demandando cuidados intensivos, está relacionado a doenças crônicas não transmissíveis que acomete o sistema circulatório e diabetes mellitus, ressalta também o índice de massa corpórea (IMC) que possui correlação com os pacientes que requerem internação hospitalar9. Diante do exposto, o presente estudo teve por objetivo analisar o perfil clínico epidemiológico dos pacientes notificados com suspeita de Covid-19 em um hospital público do Distrito Federal, Brasil.

\section{MÉTODO}

Trata-se de um estudo epidemiológico descritivo, quantitativo, com delineamento transversal, pautado em dados da ficha de registro individual de casos de Síndrome Respiratória Aguda Grave do Núcleo de Vigilância Epidemiológica (NUVEI) do Hospital Regional da Asa Norte (HRAN). O Hospital Regional da Asa Norte (HRAN) é uma unidade hospitalar, localizada em Brasília, Distrito Federal, com 367 leitos, sendo referência nos atendimentos de 
urgência/emergência, cirurgias em geral e atendimentos a vítimas de queimaduras.

A população do estudo foram todas as internações hospitalares por suspeita de Síndrome Respiratória Aguda Grave no Hospital Regional da Asa Norte (HRAN). Foram incluídas neste estudo, as internações hospitalares de indivíduos adultos no período de 01 de março a 31 de agosto de 2020 com suspeita de SRAG. Foram excluídas as internações hospitalares que apresentaram ficha de registro de caso com preenchimento incompleto, dados errôneos ou duplicados.

Os dados do estudo foram disponibilizados pelo Núcleo de Vigilância Epidemiológica (NUVEI) do Hospital Regional da Asa Norte (HRAN). As variáveis do estudo foram escrutinadas em duas categorias: aspectos sociodemográficos (sexo, faixa etária e raça/cor) e aspectos clínicos (sinais e sintomas, fatores de risco/comorbidades e resultado da RT-PCR).

A coleta de dados ocorreu em etapa única no período compreendido entre 01 e 10 de março de 2021. Os dados coletados foram devidamente organizados em planilha de dados do Microsoft Excel 2016 e análise estatística descritiva realizada por meio de frequência absoluta e frequência relativa. Para análise dos dados referente ao perfil clínico das hospitalizações, foi realizado o ajuste do $\mathrm{N}$ do estudo,

devido ao elevado número de ficha de registro individual de casos de Síndrome Respiratória Aguda Grave sem o preenchimento das informações.

Este estudo obedeceu aos preceitos estabelecidos pela Resolução $n^{\circ}$ 466/2012 do Conselho Nacional de Saúde. Iniciou- se após aprovação no Comitê de Ética em Pesquisa da Fundação de Ensino e Pesquisa em Ciências da Saúde, sob o parecer $n^{\circ}$ 4.498.459, e autorização do Núcleo de Vigilância Epidemiológica e da Direção Hospitalar mediante rubrica do Termo de Anu- ência Institucional.

\section{RESULTADOS}

De março a agosto de 2020 foram registradas 2785 internações hospitalares de casos suspeitos de infecção pelo novo coronavírus no HRAN. Observou-se maior prevalência de hospitalizações no sexo masculino $(53,47 \%)$ em comparação ao sexo feminino com (46,53\%), conforme Figura 1.

A média da idade dos pacientes hospitalizados foi de 52,25 anos, conforme Tabela 1. O valor do primeiro quartil (Q1) indica que 25\% dos indivíduos observados possuem idade menor ou igual a 40 anos, enquanto $75 \%$ dos indivíduos tinham idade $>40$ anos. $\mathrm{O}$ valor do percentil 95 significa que 95\% dos indivíduos hospitalizados possuem até 83 anos. A moda indica que a idade mais frequente entre os pacientes foi de 57 anos e a mediana (54 anos) representa a idade da metade dos individuos.

Figura 1. Distribuição das internações por suspeita de COVID-19, segundo sexo, Brasília, Brasil, 2021.

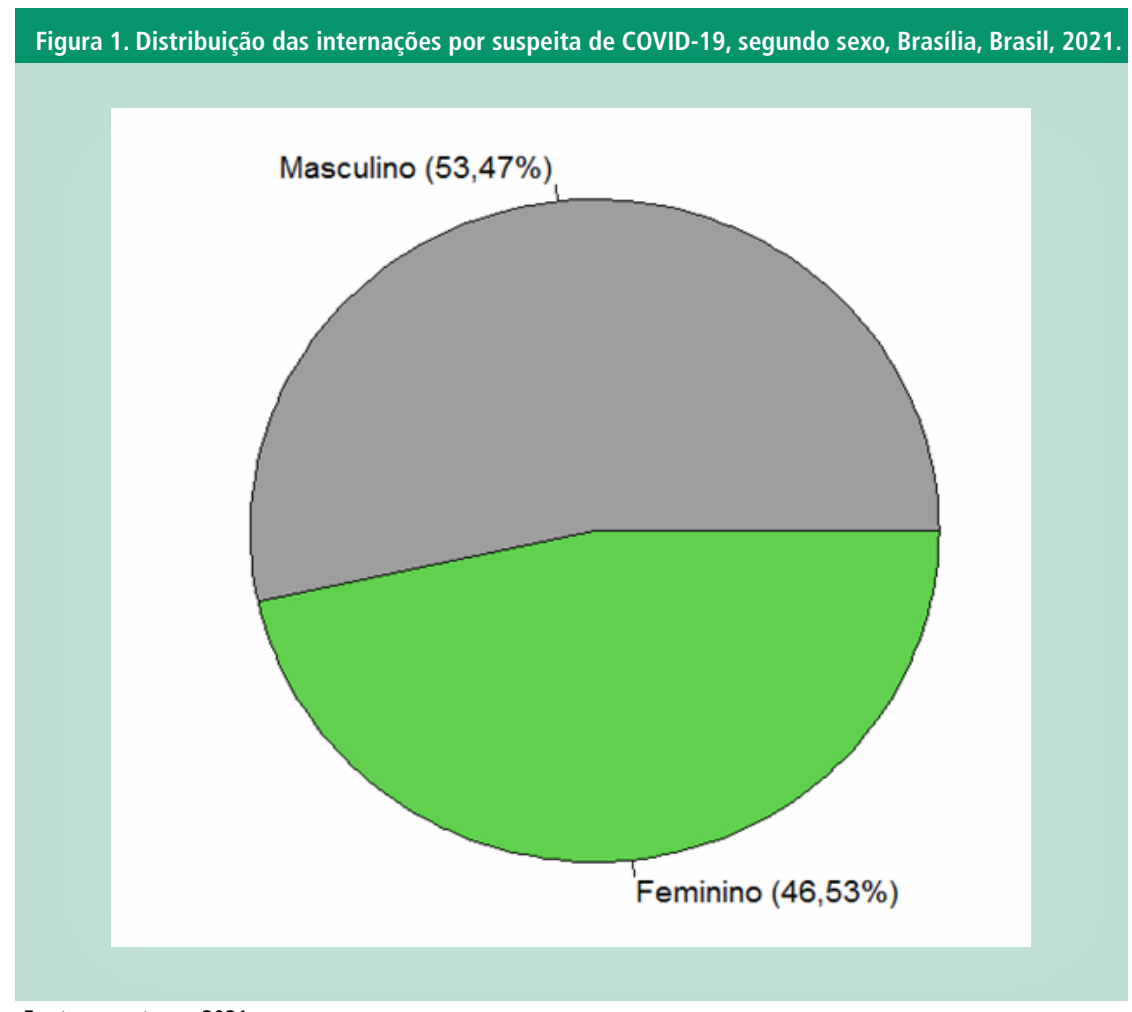

Fonte: os autores, 2021

Em relação a variável raça/cor, verificou-se que $75,03 \%$ das internações não possuíam registros de raça/cor, indígenas (17.08\%), branca $(6,19 \%)$, preta $(1,41 \%)$ e amarela $(0,21 \%)$. A tabela 2 apresenta o perfil clínico das internações hospitalares por suspeita de COVID-19. Verificou-se que $86,90 \%$ dos pacientes apresentaram dispneia, $84,58 \%$ tosse, $80,21 \%$ febre e $71,83 \%$ apresentaram Saturação O2 <95\%. Em relação à comorbidades, observou-se que $66,55 \%$ dos pacientes possuíam doença cardiovascular crônica, e $42,81 \%$ eram portadores de diabetes mellitus (DM).

Ao proceder com a análise do perfil clínico das hospitalizações segundo sexo, verificou-se maior prevalência de dispneia $(47,62 \%)$, tosse $(47,32 \%)$, e febre $(45,36 \%)$ em indivíduos do sexo masculino. E maior prevalência de vômitos $(5,00 \%)$ em indivíduos do sexo feminino, conforme Tabela 3.

No que tange ao exame RT-PCR, $63.40 \%$ dos pacientes tiveram amostra 
Tabela 1 - Coeficiente de variação (CV), média, moda, mediana, primeiro quartil (Q1) e percentil 95 (P95) referente à variável idade, Brasilia, Brasil, 2021.

\begin{tabular}{|cc|}
\hline Estatísticas & Resultados \\
\hline CV & $38,24 \%$ \\
\hline Média & 52,25 \\
\hline Moda & 57,00 \\
\hline Mediana & 54,00 \\
\hline Q1 & 40,00 \\
\hline P95 & 83,00 \\
\hline
\end{tabular}

Fonte: os autores, 2021

detectável para SARS-CoV-2, e 22,94\% não detectável.

\section{DISCUSSÃO}

O perfil sociodemográfico dos pacientes hospitalizados por suspeita de infecção pelo SARS-CoV-2 evidenciou maior percentual de internações em individuos do sexo masculino $(53,47 \%)$. Estudo realizado em um hospital federal do Rio de Janeiro identificou maior prevalência de internações entre o sexo feminino (52,90\%)10. Pesquisa realizada no Hospital Israelita Albert Einstein, em São Paulo (SP) constatou maior percentual de individuos do sexo feminino $(68,10 \%) 9$. Pesquisa em 351 prontuários de pacientes internados com coronavírus-19, observou maior percentual entre homens $(74,10 \%) 11$.

No que tange a idade dos pacientes, a média da idade registrada foi de 52,25 anos. Pesquisa em uma unidade hospitalar observou maior percentual de hospitalizações entre individuos na faixa etária de 50 a 69 anos10. Pesquisa realizada em São Paulo identificou maior concentração de casos na faixa etária 50 a 64 anos9. Pesquisa constatou maior prevalência de hospitalizações entre individuos na faixa etária de 70 a 79 anos11. Estudo identificou no estudo realizado Hospital Universitário de Brasília (HUB), a média de idade de 64,6 anos13. Os estudos apontam
Tabela 2. Perfil clínico das internações hospitalares por suspeita de COVID-19, Brasilia, Brasil, 2021.

\begin{tabular}{|c|c|c|c|c|}
\hline Variável & $\begin{array}{c}\text { N ajustado } \\
(\%)\end{array}$ & $\operatorname{Sim}(\%)$ & Não (\%) & $\begin{array}{l}\text { Ignorado } \\
(\%)\end{array}$ \\
\hline Febre & $\begin{array}{c}2.628 \\
(94,36 \%)\end{array}$ & 80,21 & 18,11 & 1,67 \\
\hline Tosse & $\begin{array}{c}2.665 \\
(95,69 \%)\end{array}$ & 84,58 & 14,45 & 0,98 \\
\hline Dor de garganta & $\begin{array}{c}2.287 \\
(82,12 \%)\end{array}$ & 11,59 & 85,31 & 3,1 \\
\hline Dispneia & $\begin{array}{c}2.642 \\
(94,87 \%)\end{array}$ & 86,90 & 12,57 & 0,53 \\
\hline Desconforto respiratório & $\begin{array}{c}2.415 \\
(86,71 \%)\end{array}$ & 60,17 & 39,01 & 0,83 \\
\hline Saturação $02<95 \%$ & $\begin{array}{c}2.364 \\
(84,88 \%)\end{array}$ & 71,83 & 27,03 & 1,14 \\
\hline Diarreia & $\begin{array}{c}2.325 \\
(83,48 \%)\end{array}$ & 16,73 & 81,55 & 1,72 \\
\hline Vômito & $\begin{array}{c}2.281 \\
(81,90 \%)\end{array}$ & 9,51 & 88,6 & 1,89 \\
\hline $\begin{array}{c}\text { Doença Cardiovascular } \\
\text { Crônica }\end{array}$ & $\begin{array}{c}1.743 \\
(62,59 \%)\end{array}$ & 66,55 & 32,99 & 0,46 \\
\hline Diabetes Mellitus & $\begin{array}{c}1.689 \\
(60,65 \%)\end{array}$ & 42,81 & 56,36 & 0,83 \\
\hline Pneumopatia Crônica & $\begin{array}{c}1.652 \\
(59,32 \%)\end{array}$ & 12,77 & 86,14 & 1,09 \\
\hline
\end{tabular}

Fonte: os autores, 2021

Tabela 3. Perfil clínico das internações hospitalares por suspeita de COVID-19, segundo sexo, Brasília, Brasil, 2021.t

\begin{tabular}{rccccc}
\multicolumn{2}{c}{ Variável } & Masculino & $\mathbf{( \% )}$ & Feminino & (\%) \\
& Sim & 1192 & $45,36 \%$ & 916 & $34,86 \%$ \\
Febre & Não & 197 & $7,50 \%$ & 279 & $10,62 \%$ \\
& Ignorado & 28 & $1,07 \%$ & 16 & $0,61 \%$ \\
\hline \multirow{2}{*}{ Tosse } & Sim & 1261 & $47,32 \%$ & 993 & $37,26 \%$ \\
& Não & 157 & $5,89 \%$ & 228 & $8,56 \%$ \\
\hline \multirow{2}{*}{ Dor de } & Ignorado & 19 & $0,71 \%$ & 7 & $0,26 \%$ \\
Garganta & Sim & 143 & $6,25 \%$ & 122 & $5,33 \%$ \\
& Não & 1026 & $44,86 \%$ & 925 & $40,45 \%$ \\
\hline \multirow{2}{*}{ Dispneia } & Ignorado & 43 & $1,88 \%$ & 28 & $1,22 \%$ \\
& Sim & 1258 & $47,62 \%$ & 1038 & $39,29 \%$ \\
& Não & 148 & $5,60 \%$ & 184 & $6,96 \%$ \\
\hline & Ignorado & 9 & $0,34 \%$ & 5 & $0,19 \%$
\end{tabular}




\begin{tabular}{cccccc} 
& Sim & 825 & $34,16 \%$ & 628 & $26,00 \%$ \\
Desconforto & Não & 448 & $18,55 \%$ & 494 & $20,46 \%$ \\
Respiratório & Ignorado & 11 & $0,46 \%$ & 9 & $0,37 \%$ \\
& Sim & 964 & $40,78 \%$ & 734 & $31,05 \%$ \\
\hline \multirow{2}{*}{ Saturação } & Não & 274 & $11,59 \%$ & 365 & $15,44 \%$ \\
\hline $02<95 \%$ & Ignorado & 16 & $0,68 \%$ & 11 & $0,47 \%$ \\
& Sim & 196 & $8,43 \%$ & 193 & $8,30 \%$ \\
\hline \multirow{2}{*}{ Diarreia } & Não & 1007 & $43,31 \%$ & 889 & $38,24 \%$ \\
& Ignorado & 28 & $1,20 \%$ & 12 & $0,52 \%$ \\
\hline \multirow{2}{*}{ Vômito } & Sim & 103 & $4,52 \%$ & 114 & $5,00 \%$ \\
& Não & 1067 & $46,78 \%$ & 954 & $41,82 \%$ \\
& Ignorado & 31 & $1,36 \%$ & 12 & $0,53 \%$ \\
\hline \multirow{2}{*}{ Outros Sinais } & Sim & 753 & $30,57 \%$ & 705 & $28,62 \%$ \\
\cline { 2 - 5 } & Não & 463 & $18,80 \%$ & 377 & $15,31 \%$ \\
\hline & Ignorado & 90 & $3,65 \%$ & 75 & $3,05 \%$
\end{tabular}

Fonte: os autores, 2021

a idade avançada como um determinante importante na necessidade de procura por assistência médica, e correlacionam a idade avançada como dois condicionante importante para o prognóstico do SARS-CoV-2.

Em relação à presença de comorbidades, evidenciou-se que $66,55 \%$ dos pacientes apresentavam doença cardiovascular crônica $(66,55 \%)$ e diabetes mellitus $(42,81 \%)$. Estudo em uma unidade hospitalar, observou-que $25,00 \%$ dos indivíduos possuíam hipertensão arterial e 20,00\% diabetes mellitus 13 . Em estudo realizado no Hospital Israelita Albert Einstein constatou-se que $20,80 \%$ dos pacientes eram hipertensos e $13,90 \%$ portadores de diabetes mellitus9. As doenças pré-existentes ou comorbidades como hipertensão arterial, diabetes e doença pulmonar obstrutiva crônica são fatores de risco para evolução de desfechos desfavoráveis em indivíduos com COVID-19, e contribuem para maior tempo de internação e mortalidade13. A existência de comorbidades que segundos alguns autores impactam na evolução clínica da doença. Assim afirmam em estudos que indivíduos com múltiplas comorbidades possuem risco de óbito aumenta- do em 9,44 vezes comparado ao grupo sem doenças prévias14.

A dispneia, tosse e febre foram os sinais/sintomas que apresentaram maior prevalência no presente estudo. Pesquisa sobre o perfil clínico dos pacientes de uma unidade hospitalar apontou que $80,60 \%$ dos pacientes hospitalizados apresentaram febre, $11,11 \%$ dispneia e $23,60 \%$ tosse 8 . Os individuos que apresentam sintomas gripais, febre e mialgia, são consideras casos da forma considerada leve, na forma moderada há queixas de dispneia aos esforços moderados e intensos associados aos sintomas gripais, já na forma grave, os pacientes necessitam que suporte ventilatório15.

As mulheres apresentaram maior percentual de vômitos $(5,00 \%)$, quando comparadas com o sexo masculino. Contudo, na literatura consultada não foram encontradas evidências para discussão deste resultado. O resultado molecular para COVID-19 identificou que $63,4 \%$ dos pacientes tiveram resultado detectável (positivo). O exame RT-PCR é considerado padrão ouro para o diagnóstico precoce, podendo estar vinculado quando necessário a solicitação de outros exames que corrobora no afastamento ou validação da infecção16.

\section{CONCLUSÃO}

O perfil clínico epidemiológico das hospitalizações por suspeita de infecção pelo coronavírus no Hospital Regional da Asa Norte (HRAN), demonstrou maior prevalência entre os homens $(53,47 \%)$, com média de idade de 52,25 anos, portadores de doença cardiovascular crônica, com presença de dispneia, tosse e febre.

As potencialidades deste estudo consistiram na elucidação do perfil clínico epidemiológico dos pacientes assistidos pelo Hospital Regional da Asa Norte. Em relação as limitações do estudo, mencionamos a ausência no preenchimento das informações sobre raça/cor e nas variáveis relacionados ao perfil clínico do adoecimento pela COVID-19. Ressaltamos a importância do preenchimento completo da ficha de notificação realizado pelo profissional responsável, dado que estas informações poderão ser úteis na elaboração de pesquisas a fim de contribuir com as autoridades competentes na implementação de barreiras sanitárias contra o COVID-19.

Concluímos que ainda existem muitas lacunas incompreendidas acerca do novo coronavírus, mas que a vacinação em massa da população mundial com os inúmeros imunizantes desenvolvidos e em fase de progresso dará tempo hábil a elaboração de políticas nacionais e internacionais na irradicação desse vírus assim 


\section{Referências}

1. World Health Organization - WHO. WHO Director-General's statement on IHR Emergency Committee on Novel Coronavirus (2019-nCoV). Disponível em: < https://www.who.int/dg/speeches/detail/who-director-general-s-statement-on-ihr- emergency-committee-on-novel-coronavirus-(2019-ncov)>. Acesso em: 11 abr 2020

2. Roque e Lima, JO. A pandemia da COVID 19 sob a ótica dos profissionais de enfermagem: a luta pela valorização profissional. Nursing (São Paulo), v. 23, n. (268), 4543, 2020.

3. Oliveira GMM, Pinto FJ. COVID-19: Um Assunto do Coração. International Journal of Cardiovascular Sciences.

4. Brasil. Universidade Aberta do SUS UMA-SUS. Coronavírus: Brasil confirma primeiro caso da doença [Internet]. Notícias. Fev, 2020. Disponível em: https:// www.unasus.gov.br/noticia/coronavirus-brasil-confirma-primeiro-caso-da-doenca/Acessado em 12 de junho de 2021.

5. Dasa Analytics. Dados COVID- 19 [Internet]. Disponivel em: https://dadoscoronavirus.dasa.com.br/\#lp-pom-block-195/ Acessado em 19 de julho de 2021.

6. Brasil. Ministério da Saúde. Plano Nacional de Operacionalização da Vacinação Contra a Covid-19. $6^{a}$ edição (versão 3), Brasília-DF. Disponível em ; <https://www.conasems.org.br/wp-content/uploads/2021/04/planonacionaldevacinacaocovid19ed06v328.04.pdf/Acessado em: 06 de jun de 2021.

7. Souza et al. Evolução espaçotemporal da letalidade por COVID-19 no Brasil, 2020. J Bras Pneumol. São Paulo, v. 46, n. 4,p. 1-2, 2020.

8. Brasil. Ministério da Saúde. Painel de casos de doença pelo coronavírus (COVID-19) no Brasil pelo Ministério da Saúde. Disponível em <https://covid.saude. gov.brl. Acessado em: 22 de ago de 2020.

9. Teich VD et al. Características epidemiológicas e clínicas dos pacientes com
COVID-19 no Brasil. Einstein, São Paulo, v.18, p. 1-7, 2020.

10. Escosteguy CC et al. COVID-19: estudo seccional de casos suspeitos internados em um hospital federal do Rio de Janeiro e fatores associados ao óbito hospitalar. Epidemiol. Serv. Saúde, Brasília, v. 30, n. 1, p. 1-12, 2021

11. Zavaleta $\mathrm{MH}$ et al. Características e fatores de risco para mortalidade em pacientes hospitalizados por covid -19 em um hospital público em Tacna. Scientific Electronic Library Online [Internet]. 2021 Jan 26 [cited 2021 Jun 12]; DOI https://doi.org/10.1590/SciELOPreprints.1764. Available from: https://preprints. scielo.org/index.php/scielo/preprint/view/1764/2812

12. Batuecas- Duelt IJ et al. Perfil de los pacientes hospitalizados em dispositivos assistenciales habilitados durante la pandemia por SARS-CoV-2. Metas Enferm. Valença, v. 23, n. 7, p. 7-15, nov. 2020.

13. Santos PSA et al. Perfil epidemiológico da mortalidade de pacientes internados por Covid-19 na unidade de terapia intensiva de um hospital universitário. Brazilian Journal of Development, Curitiba, v.7, n.5, p. 45981-45992, maio, 2021.

14. Galvão MH, Roncalli AG. Fatores associados a maior risco de ocorrência de óbito por COVID-19: análise de sobrevivência com base em casos confirmados. Rev. bras. Epidemiol. São Paulo, v, 23: E200106, 2020.

15. Rothan HA, Byrareddy SN. A epidemiologia e patogênese do surto de doença coronavírus (COVID-19).Journal of Autoimmunity, v.109, 102433, maio. 2020.

16. Dias VM et al. Orientações sobre Diagnóstico, Tratamento e Isolamento de Pacientes com COVID-19. J. Infect. Control, v.9, n. 2, p. 1-20 Abr-Jun, 2020. 